Supporting Information for:

\title{
Oil-in-Oil Emulsions Stabilized by Asymmetric Polymersomes Formed by AC + BC Block Polymer Co-Assembly
}

\author{
Itaru Asano, ${ }^{\dagger, \S}$ Soonyong So, ${ }^{\ddagger}$ and Timothy P. Lodge*, ${ }^{* \dagger \dagger}$ \\ ${ }^{\dagger}$ Department of Chemistry and ${ }^{\ddagger}$ Department of Chemical Engineering \& Materials Science, \\ University of Minnesota, Minneapolis, Minnesota 55455, United States \\ ${ }^{\S}$ Chemicals Research Laboratories, Toray Industries, Inc., 9-1, Oe-cho, Minato-ku, Nagoya, \\ 455-8502, Japan
}




\section{CHARACTERIZATION METHODS}

${ }^{1}$ H NMR spectroscopy. ${ }^{1} \mathrm{H}$ NMR spectra were measured on a VARIAN UNITY 300 spectrometer at $300 \mathrm{MHz}$ at $25{ }^{\circ} \mathrm{C}$ in $\mathrm{CDCl}_{3} . M_{\mathrm{n}}$ of the PS and PB blocks were calculated from the integral comparison of hydroxyl terminated PS (PS-OH) or hydroxyl terminated PB (PB-OH) between phenyl protons of PS-OH $(6.3-7.5 \mathrm{ppm})$ or methylene protons $(4.5-5.5 \mathrm{ppm})$ of PB$\mathrm{OH}$ and methylene protons adjacent to the hydroxyl end $(3.5-3.7 \mathrm{ppm}) . M_{\mathrm{n}}$ of PEO block was determined by calculating the integral between the phenyl protons of SO or methylene protons of $\mathrm{BO}$ and the methylene protons $(3.5-3.7 \mathrm{ppm})$.

Size Exclusion Chromatography (SEC). All samples were prepared by dissolving in THF at $0.5 \mathrm{wt} \%$. The SEC consists of an LC Agilent 1260 Infinity equipped with a Wyatt DAWN DSP multiangle light scattering detector, a variable wavelength UV-vis detector and three Waters Styragel columns (HR6, HR4, HR1, Dimension; $7.8 \mu \mathrm{m} \times 300 \mathrm{~mm}$ ). Operating conditions of THF flow rate, temperature and wavelength of UV-vis detector were $1.0 \mathrm{~mL} / \mathrm{min}, 25^{\circ} \mathrm{C}$ and 254 $\mathrm{nm}$, respectively. Residual $\mathrm{RhoBCl}$ included in the resulting dye-labeled polymer was quantified by SEC with a UV-vis detector. RhoBCl itself shows absorption intensity at $31 \mathrm{~min}$. Standard curve was plotted taking that intensity as a function of the concentration of $\mathrm{RhoBCl}$ ranging from $0.1-2.5 \times 10^{-4} \mathrm{wt} \%$, which is expressed in $y=2909 x+0.0161$ (Regression value $\left.\approx 1\right)$, where $y$ is absorption intensity and $x$ is the concetration of $\mathrm{RhoBCl}$. The dye-attached polymer shows no peak around $31 \mathrm{~min}$, indicating $\mathrm{RhoBCl}$ is at most $0.002 \mathrm{wt} \%$ in polymer.

UV-visible Spectroscopy. Absorption spectra were obtained on a Varian Cary 100Bio Uv-vis spectrophotometer at $25^{\circ} \mathrm{C}$. Samples were prepared by dissolving polymer in THF at $0.04 \mathrm{wt} \%$.

\section{SAMPLE PREPARATION}

Materials. Styrene (St), Butadiene (Bd), ethylene oxide (EO), rhodamine B base, $n$-butyllithium, sec-butyllithium, n-butylmagnesium chloride, potassium, naphthalene, 1,2-dichloroethane, phosphorous oxychloride, anhydrous pyridine, methanol (MeOH), isopropanol (IPA), pentane, chloroform $\left(\mathrm{CHCl}_{3}\right)$, cyclohexane $(\mathrm{CHX})$, tetrahydrofuran $(\mathrm{THF})$, fluorescein were purchased 
from Sigma-Aldrich. Polyethylene glycol (PEG) was purchased from Fluka $\left(M_{\mathrm{n}}=32 \mathrm{~kg} / \mathrm{mol}, \emptyset\right.$ $=1.03)$. These materials were used as received, except that $\mathrm{CHX}$ and THF were purified by passing through an activated alumina column twice with purging argon, St was purified twice by $n$-butylmagnesium chloride, and Bd and EO were purified twice by $n$-butyllithium, respectively. Potassium naphthalenide was prepared by mixing potassium metal and naphthalene into THF under argon.

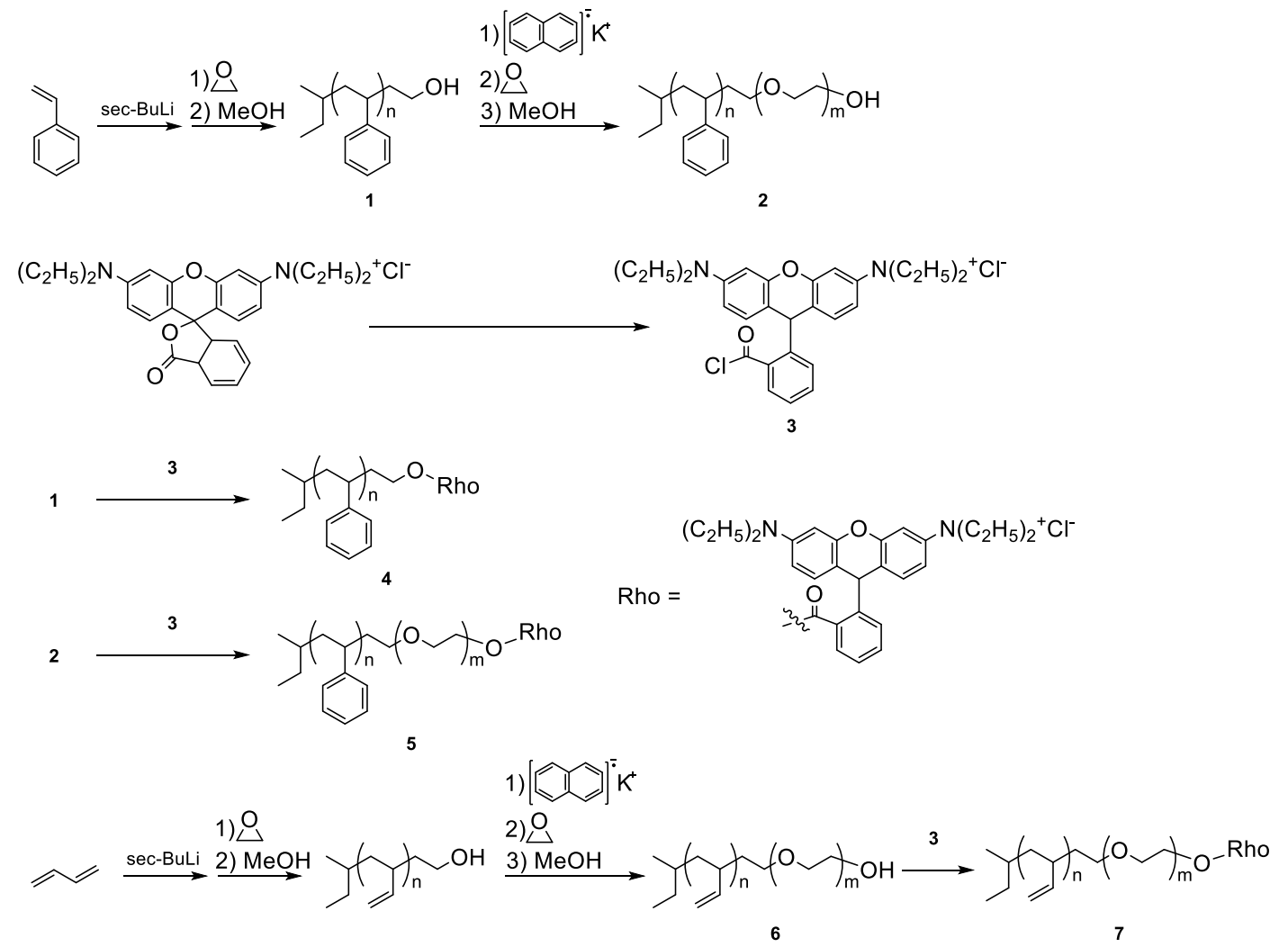

Figure S1. Synthetic route to all samples: (1) PS-OH, (2) SO, (3) RhoBCl, (4) PS*, (5) $\mathrm{SO}^{*}$, (6) $\mathrm{BO}$, and (7) $\mathrm{BO} *$, respectively.

\section{Synthesis of hydroxyl-terminated polystyrene (PS-OH) and polystyrene-b-poly(ethylene}

oxide) (SO). SO was prepared by sequential living anionic polymerization starting with PS-OH and subsequent chain growth polymerization of EO. St monomer was initiated by secbutyllithium and polymerized in $\mathrm{CHX}$ at $45^{\circ} \mathrm{C}$ for $5 \mathrm{~h}$. After adding excess $\mathrm{EO}$, the reaction 
proceeded at $45{ }^{\circ} \mathrm{C}$ for $20 \mathrm{~h}$ and deoxygenated $\mathrm{MeOH}$ was added to the reactor to produce hydroxyl-terminated PS (PS-OH). PS-OH was isolated after precipitation in $\mathrm{MeOH}$ and dried under vacuum. PS-OH was dissolved in THF and anionically charged by adding potassium naphthalenide. EO was added at r.t. and the reaction proceeded at $45{ }^{\circ} \mathrm{C}$ for $24 \mathrm{~h}$. SO was terminated by deoxygenated $\mathrm{MeOH}$ and precipitated in a MeOH/IPA mixture and isolated by drying under vacuum. ${ }^{1} \mathrm{H}$ NMR spectroscopy and SEC were used to measure $M_{\mathrm{n}}$ and the dispersity $(\nexists)$, respectively. Three different SOs were prepared via the above procedure with controlled volume fraction $\left(f_{\mathrm{PEO}}\right)$ by varying the molar ratio of PS-OH and EO. ${ }^{1} \mathrm{H}$ NMR $(300$ $\left.\mathrm{MHz}, \mathrm{CDCl}_{3}\right)$ for PS-OH: $\delta=6.25-7.25 \mathrm{ppm}\left(-\mathrm{C} \underline{\mathrm{H}}_{5}, \mathrm{br}, 5 \mathrm{H}\right), 3.4-3.6 \mathrm{ppm}\left(-\mathrm{C}_{2} \underline{\mathrm{OH}}, \mathrm{br}, 2 \mathrm{H}\right)$, $1.2-2.0$ ppm (- $\underline{\mathrm{C}}_{2} \mathrm{C} \underline{\mathrm{HC}} 6 \mathrm{H} 5-$, br, $\left.3 \mathrm{H}\right)$. SO: $\delta=6.25-7.25$ ppm (-C6 $\left.\underline{\mathrm{H}}_{5}, \mathrm{br}, 5 \mathrm{H}\right), 3.4-3.7 \mathrm{ppm}(-$ $\mathrm{C}_{2} \mathrm{CH}_{2} \mathrm{O}-$, br, 4H), $1.2-2.0$ ppm (- $\underline{\mathrm{CH}}_{2} \mathrm{CHC} 6 \mathrm{H} 5-$, br, 3H).

Synthesis of rhodamine B acid chloride (RhoBCl). RhoBCl was prepared through the reaction between Rhodamine B base $(2.3 \mathrm{mmol})$ and phosphorous oxychloride $(6.5 \mathrm{mmol})$ in 1,2dichloroethane $(12 \mathrm{~mL})$ under reflux for $20 \mathrm{~h}$. The volatiles were removed under vacuum and RhoBCl was used for the next reaction without further purification. ${ }^{1} \mathrm{H}$ NMR $\left(300 \mathrm{MHz}, \mathrm{CDCl}_{3}\right)$ for RhoBCl: $\delta=8.53 \mathrm{ppm}(-\mathrm{Ar} \underline{\mathrm{H}}, \mathrm{d}, 1 \mathrm{H}), 8.00 \mathrm{ppm}(-\mathrm{Ar} \underline{\mathrm{H}}, \mathrm{t}, 1 \mathrm{H}), 7.87 \mathrm{ppm}(-\mathrm{ArH}, \mathrm{t}, 1 \mathrm{H}), 7.50$ ppm ( -Ar $\underline{\mathrm{H}}, \mathrm{d}, 1 \mathrm{H}), 7.03$ ppm (-Ar $\underline{\mathrm{H}}, \mathrm{d}, 2 \mathrm{H}), 6.87 \mathrm{ppm}(-\mathrm{Ar} \underline{\mathrm{H}}, \mathrm{d}, 4 \mathrm{H}), 3.62 \mathrm{ppm}\left(-\mathrm{N}\left(\mathrm{C}_{2} \mathrm{CH}_{3}\right)_{2}\right.$, q, $8 \mathrm{H}), 1.34$ ppm $\left(-\mathrm{N}\left(\mathrm{CH}_{2} \mathrm{CH}_{3}\right)_{2}, \mathrm{t}, 12 \mathrm{H}\right)$.

Rhodamine B-labeled PS (PS*) and Rhodamine B-labeled SO (SO*). PS* and SO* were prepared by end-hydroxyl group esterification of PS-OH or SO with RhoBCl. PS or SO and 3M excess $\mathrm{RhoBCl}$ were dissolved in $\mathrm{CHCl}_{3}$ under argon atmosphere, anhydrous pyridine (the same molar as $\mathrm{RhoBCl}$ ) was added, and the mixture was heated to $40^{\circ} \mathrm{C}$ and the reaction allowed to proceed for $48 \mathrm{~h}$. The reaction was quenched by adding excess $\mathrm{MeOH}$. The product was precipitated in a selective solvent of a $\mathrm{MeOH} / \mathrm{IPA} /$ pentene $=4 / 4 / 2$ (vol. ratio). In order to remove the remaining $\mathrm{RhoBCl}$, the product was re-dissolved in $\mathrm{CHCl}_{3}$ and poured into the above mixed solvent twice. The purified product was dried under vacuum, yielding PS* or SO* pink 
powder. The resultant PS* and SO* were characterized with SEC and Uv-vis spectroscopy. The remaining $\mathrm{RhoBCl}$ content in $\mathrm{PS}^{*}$ and $\mathrm{SO}^{*}$ were at most $0.002 \mathrm{wt} \%$, whereas UV-vis of PS* and $\mathrm{SO}^{*}$ showed absorption around $536 \mathrm{~nm}$ derived from rhodamine $\mathrm{B}$. Therefore, rhodamine B was labeled on PS and SO at the same time that almost all RhoBCl was removed.

Synthesis of polybutadiene-b-poly(ethylene oxide) (BO). Analogous to the synthetic scheme for $\mathrm{SO}$, BO was prepared by sequential living anionic polymerization starting with hydroxyl terminated polybutadiene $(\mathrm{PB}-\mathrm{OH})$ and subsequent chain growth polymerization of $\mathrm{EO}$. Bd monomer was initiated by sec-butyllithium and polymerized in $\mathrm{CHX} / \mathrm{THF}=9 / 1(\mathrm{vol} / \mathrm{vol})$ at $5^{\circ} \mathrm{C}$ for $5 \mathrm{~h}$. After adding excess EO, the reaction mixture was heated up to $45^{\circ} \mathrm{C}$ and proceeded for $20 \mathrm{~h}$; thereafter deoxygenated $\mathrm{MeOH}$ was added to the reactor to produce hydroxyl-terminated PB-OH. After the isolated PB-OH was charged into the reactor, THF was added to dissolve PB$\mathrm{OH}$, which was and anionically charged by adding potassium naphthalenide. EO was added at r.t. and the reaction proceeded at $45^{\circ} \mathrm{C}$ for $20 \mathrm{~h}$. BO was terminated by deoxygenated $\mathrm{MeOH}$ and precipitated in a MeOH/IPA mixture and isolated by drying under vacuum. ${ }^{1} \mathrm{H}$ NMR spectroscopy and SEC were used to measure $M_{\mathrm{n}}$ and the dispersity $(\nexists)$, respectively. Three different BOs were prepared via the above procedure with controlled volume fraction $\left(f_{\mathrm{PEO}}\right)$ by varying the molar ratio of $\mathrm{PB}-\mathrm{OH}$ and $\mathrm{EO} .{ }^{1} \mathrm{H} \mathrm{NMR}\left(300 \mathrm{MHz}, \mathrm{CDCl}_{3}\right)$ for $\mathrm{BO}: \delta=5.2-5.8$

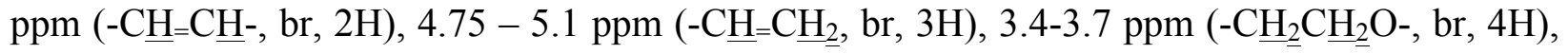

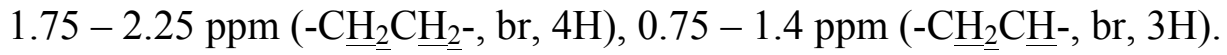

Rhodamine B-labeled BO (BO*). Analogous to the synthetic scheme for $\mathrm{SO}^{*}$, BO* was prepared by following method. $\mathrm{BO}$ and $3 \mathrm{M}$ excess $\mathrm{RhoBCl}$ were dissolved in $\mathrm{CHCl}_{3}$ under argon atmosphere, thereafter anhydrous pyridine (the same molar as RhoBCl) was added, and the mixture was heated to $40^{\circ} \mathrm{C}$. The reaction was quenched by adding excess $\mathrm{MeOH}$ after $48 \mathrm{~h}$. The product was precipitated in a selective solvent of a MeOH/IPA mixture. In order to remove the remaining $\mathrm{RhoBCl}$, the product was re-dissolved in $\mathrm{CHCl}_{3}$ and poured into the above mixed solvent for re-precipitation twice. The purified product was dried under vacuum, giving pink 
colored $\mathrm{BO}^{*}$. The resultant $\mathrm{BO}^{*}$ was characterized with SEC and Uv-vis spectroscopy. The remaining $\mathrm{RhoBCl}$ content in $\mathrm{BO}^{*}$ was quantified at most $0.002 \mathrm{wt} \%$, whereas $\mathrm{UV}$-vis of $\mathrm{BO} *$ showed absorption around $536 \mathrm{~nm}$ derived from rhodamine $\mathrm{B}$. Therefore, rhodamine $\mathrm{B}$ was labeled on $\mathrm{BO}$ without unreacted RhoBCl.

Table S1. Properties of SO and BO used for this study

\begin{tabular}{ccccc}
\hline $\mathrm{BCP}^{a}$ & $M_{\mathrm{n}}{ }^{b}(\mathrm{~kg} / \mathrm{mol})$ & $\bigoplus^{c}$ & $f_{\mathrm{PEO}}{ }^{d}$ & $\begin{array}{c}\text { RhoBCl residual } \\
(\mathrm{wt} \%)^{e}\end{array}$ \\
\hline $\mathrm{SO}(9-2)$ & 11 & 1.01 & 0.14 & $<0.002$ \\
$\mathrm{SO}(9-13)$ & 22 & 1.02 & 0.55 & $<0.002$ \\
$\mathrm{SO}(9-33)$ & 42 & 1.02 & 0.75 & $<0.002$ \\
$\mathrm{BO}(8-2)^{f}$ & 10 & 1.03 & 0.15 & $<0.002$ \\
$\mathrm{BO}(8-10)^{f}$ & 18 & 1.13 & 0.48 & $<0.002$ \\
$\mathrm{BO}(8-35)^{f}$ & 43 & 1.10 & 0.75 & $<0.002$
\end{tabular}

${ }^{a} \mathrm{SO}$ or BO with the number-average molecular weight $\left(M_{\mathrm{n}}\right)$ is described as $\mathrm{SO}(x-y)$ or $\mathrm{BO}(x-y), x$ is $M_{\mathrm{n}}$ of PS or PB block, and $y$ is $M_{\mathrm{n}}$ of PEO block determined by ${ }^{1} \mathrm{H}$ NMR, respectively. ${ }^{b} M_{\mathrm{n}}$ of block copolymer by summation of each block segment. ${ }^{c}$ Dispersity (Đ) measured by SEC. ${ }^{d}$ The volume fraction of PEO segment in block copolymer calculated based on each density: PS, PB and PEO at 1.06, 0.91 and $1.27 \mathrm{~g} / \mathrm{cm}^{3}$, respectively. ${ }^{e}$ Weight $\%$ of residual $\mathrm{RhoBCl}$ after dye-labeled esterification determined by SEC with UV-vis detector. ${ }^{f}$ Content of 1,2 -addition in PB block is $90 \%$ as determined by ${ }^{1} \mathrm{H}$ NMR.

Oil-in-oil emulsion preparation. "Emulsions were prepared by adding $\mathrm{CHCl}_{3}$ into the weighed polymer mixture. The mixtures were stirred at room temperature until dissolution of all polymers was complete."

\section{Compositions of upper and bottom layers of the oil-in-oil emulsion at $\mathrm{PS} / \mathrm{PB} / \mathrm{CHCl}_{3}=$} 15/15/70 weight ratio. Oil-in-oil emulsions were formed by mixing $\mathrm{PS} / \mathrm{PB} / \mathrm{CHCl}_{3}$ in a $15 / 15 / 70$ weight ratio. After that, the emulsion kept for more than 3 days without stirring until macroscopic phase separation occurred. Upper and bottom layers were extracted individually. The $\mathrm{CHCl}_{3}$ concentration in the upper and the bottom layers were quantified by weighing both 
before and after complete solvent evaporation. Furthermore, PS and PB ratio in both layers were measured by ${ }^{1} \mathrm{H}$ NMR with the integral comparison between phenyl group of PS (6.3 - $\left.7.5 \mathrm{ppm}\right)$ and the methylene group of PB (4.5 - 5.5 ppm). The composition of each layer is listed in Table S2. Densities were measured by weighing controlled volumes of the extracted solutions, and the volume fractions of upper and bottom layers were determined by measuring the height of each solution after macroscopic phase separation occurred.

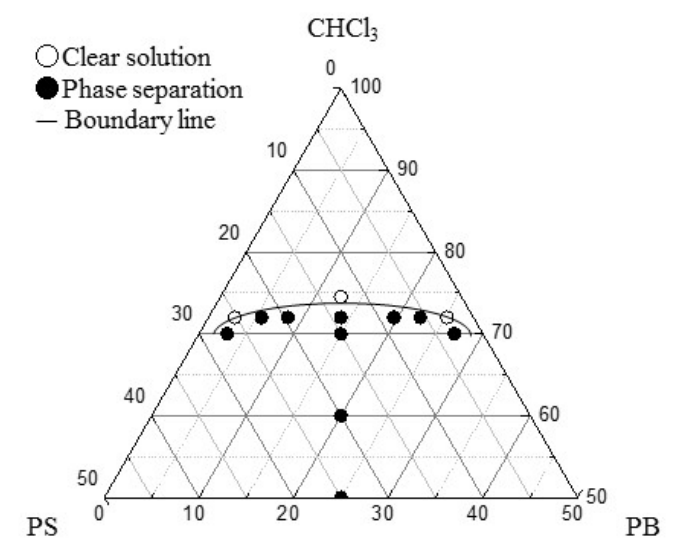

Figure S2. Ternary phase diagram for $\mathrm{PS} / \mathrm{PB} / \mathrm{CHCl} 3$ mixed system at $25^{\circ} \mathrm{C}$. The open symbols indicate a clear solution, while the solid symbols are a phase separation. The number of each axis shows the wt \% of each component. Phase separation occurred above $28 \mathrm{wt} \%$ of total polymer concentration.

Table S2. Compositions of upper and bottom layers in $\mathrm{PS} / \mathrm{PB} / \mathrm{CHCl} 3=15 / 15 / 70$ weight ratio

\begin{tabular}{ccccc}
\hline Layer & $\begin{array}{c}\mathrm{PS} / \mathrm{PB} \\
\text { ratio }\end{array}$ & $\begin{array}{c}\mathrm{CHCl}_{3} \text { content } \\
(\mathrm{wt} \%)\end{array}$ & $\begin{array}{c}\text { Density } \\
\left(\mathrm{g} / \mathrm{cm}^{3}\right)\end{array}$ & $\begin{array}{c}\text { Volume } \\
\text { fraction }\end{array}$ \\
\hline Upper & $2 / 98$ & 71.0 & 1.24 & 0.57 \\
Bottom & $98 / 2$ & 62.0 & 1.31 & 0.43 \\
\hline
\end{tabular}

CFM imaging. CFM images of both optical and fluorescence were obtained using an Olympus FV1000 BX2 Upright Confocal Microscope equipped an UPLSAPO (an objective lens, $\times 20$, $\mathrm{NA}=0.80)$ and a WHN10X-H (an eye lens, $\times 10$ ). For fluorescence imaging, the wavelength of 
the incident light was chosen as $488 \mathrm{~nm}$ or $536 \mathrm{~nm}$ for exciting fluorescein and rhodamine $\mathrm{B}$ on each dye-labeled polymer, respectively. Images were immediately acquired with $512 \times 512$ pixels after inserting the specimen, in which an aliquot of emulsion was put between a coverslip and a slide glass.

Droplet size measurement. Droplet size was obtained from at least randomly selected CFM images, whereby the number-average mean droplet size in diameter $\left(D_{\mathrm{n}}\right)$ was calculated.
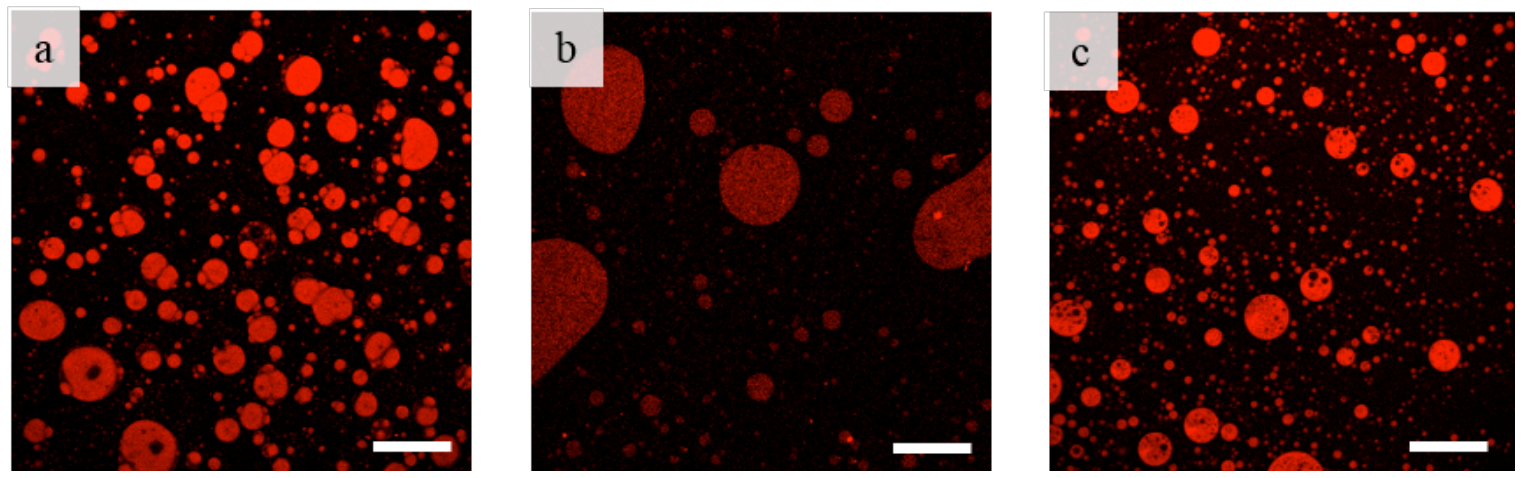

Figure S3. CFM images obtained from PS-in-PB emulsions at PS/PB/ $\mathrm{CHCl}_{3}=15 / 15 / 70$ weight ratio with a small amount of PS* and 0.5/0.5 wt \% of (a) $\mathrm{SO}(9-33) / \mathrm{BO}(8-35)$, (b) $\mathrm{SO}(9-2) / \mathrm{BO}(8-2)$, and (c) $\mathrm{SO}(9-13) / \mathrm{BO}(8-10)$, respectively. Red-phases indicate the primary PS location. Scale bars $=100 \mu \mathrm{m}$.
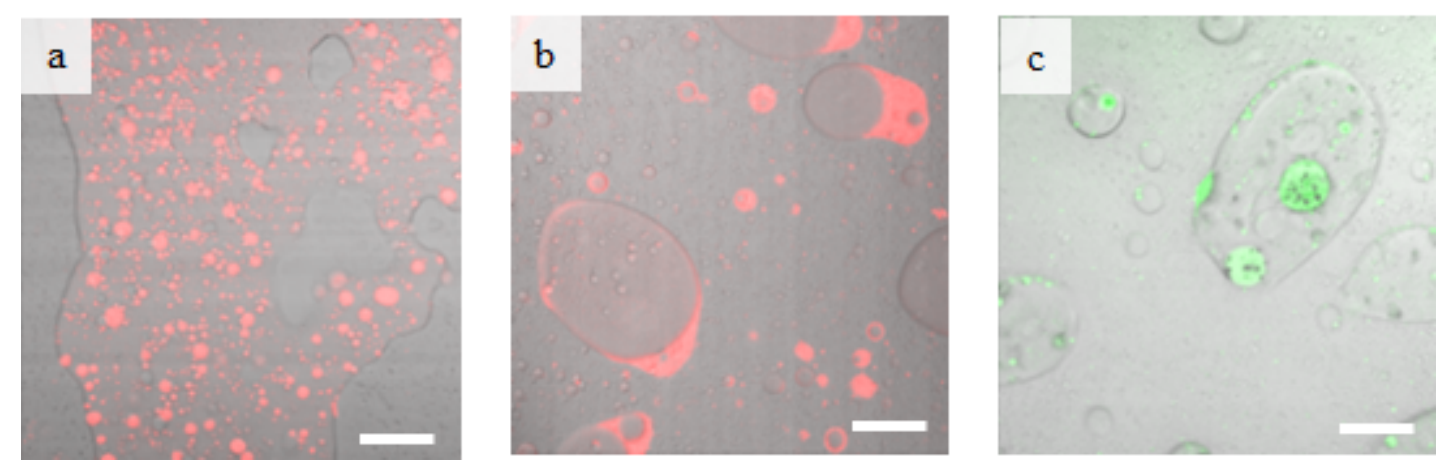

Figure S4. Overlaid optical and CFM images of PS-in-PB emulsions at $\mathrm{PS} / \mathrm{PB} / \mathrm{CHCl}_{3}=$ 15/15/70 weight ratio with $\mathrm{SO}(9-33)^{*}, \mathrm{BO}(8-35)^{*}$ and $\mathrm{PEG}$, respectively. Red-phase in (a) and (b) indicates SO and BO, and green-phase in (c) indicates PEG phase solvated with fluorescein, respectively. Scale bars $=10 \mu \mathrm{m}$. 